\title{
Truth, Narrative, and Opening Space
}

\author{
Matthew Z. Donnelly \\ Philosophy, Boston College, Chestnut Hill, USA \\ Email: mdonnel4@gmail.com
}

Received July 11 ${ }^{\text {th }}$, 2012; revised August 15 ${ }^{\text {th }}$, 2012; accepted August $26^{\text {th }}, 2012$

\begin{abstract}
This paper identifies the difficulties in confronting novel history from both a rigorous scientific and artistic literary perspectives and suggests a practical reconciliation - in the form of a discussion and metaphorical opening space- - between the two apparent poles of historical understanding and their accompanying genres, types, and tropes.
\end{abstract}

Keywords: Narrative History; Historiography; Narrative Theory; Literary Genres; Philosophy of History

\section{Introduction}

The practice of history is fraught with disciplinary difficulties. Like many liberal arts, history is pulled in two directions, toward the institutional rigor of empirical science and toward the expressive and culturally dynamic realm of creative art. Hayden White describes a common response by the historian:

For better than a century many historians have found it useful to employ a Fabian tactic against critics in related fields of intellectual endeavor. The tactic works like this: when criticized by social scientists ${ }^{1}$ for the softness of his method, the crudity of his organizing metaphors, or the ambiguity of his sociological and psychological presuppositions, the historian responds that history has never claimed the status of a pure science... But when reproached by literary artists for his failure to probe the more arcane strata of human consciousness and his unwillingness to utilize contemporary modes of literary representation, the historian falls back upon the view that history is after all a semi-science... (White, The Burden of History, 1978)

This tension is acute when confronting extreme or novel historical events such as the Holocaust or the employment of nuclear weapons. This tension is particularly acute because such events naturally invite, and indeed require, both artistic and scientific study. By the events' very novelty, society is drawn to confront and integrate the events into human narrative. For example, both comprehensive scientific and artistic descriptions of the 20th century would be incomplete without including the Holocaust. On the other hand, an artistic narrative of the 20th century could still be comprehensive without including string theory; a scientific narrative could still be comprehensive without Citizen Kane. Novel historical invite require comprehensive and diverse treatment, while mundane events do not. The purpose of this paper is to identify the difficulties in confronting novel history from both the rigorous scientific and artistic literary perspectives and to suggest a practical reconciliation-in the form of a discussion and metaphorical opening spacebetween the two apparent poles of historical understanding and

${ }^{1}$ One could easily see empirical scientists leveling similar charges against the historian. their accompanying genres, types, and tropes. ${ }^{2}$

Some theorists, such as Hayden White, hold that "Contemporary Western man has good reason to be obsessed by his sense of the uniqueness of his problems and is justifiably convinced that the historical record as presently provided offers little help in the quest for adequate solutions to those problems" (White, The Burden of History, 1978: p. 41). The uniqueness of Western society certainly seems to be a misattribution of importance by White. Indeed, if the modern context has taught us nothing else, it has revealed the global ${ }^{3}$ scope and impact of human interaction. Any limited context, be it Western or otherwise, assumes a characteristic of normality that claims unwarranted privilege. The West (or any other privileged perspective or context) should not be treated as the critical realm of history. It seems to me that the temporal perspective of Contemporary Western man also fails to establish any qualitative uniqueness vis a vis historical experience. To say that the experiences of the last century are unique is to bring historical difference to the point of triviality and banality. Of course the world had never experienced nuclear weapons or genocide on the scale experienced in the twentieth century. Similarly, the world had never experienced, and has not experienced since, the erection of the pyramids of Egypt by an enslaved race. Additionally, while technology and other implements of the modern age such as new forms of government and social control may have made mass genocide possible, so too did the increase in human population. Millions of individuals could not have been killed, for example, in ancient Greece, because there were simply not millions of people in ancient Greece. The novelty of the modern experience has as much, if not more, to do with the novelty of every historical experience as it does with the novel qualities and types of influences that made it possible. Any understanding of uniqueness is relative to the scope and "level

\footnotetext{
${ }^{2}$ Additionally, what constitutes a piece of history, as opposed to a piece of art or science, should be taken quite liberally. Because we are indeed engaged in a discussion of the scope and function of narrative history itself, there should be no arbitrary or potentially arbitrary limits on what falls into the scope of this discussion. The form, function, and life of narrative history is the subject of our investigation, rather than whether or not a particular piece instantiates such form, function, or academic life.

${ }^{3}$ Rather than regional.
} 
of precision” of historical inquiry (Ricoeur, 1984: p. 124). Therefore, in investigating the way narrative history treats novel and extreme history, we should assume neither a western nor a modern arrogance. We do not want to be so precise as to elevate the novelty of such events to triviality or so general as to exclude an understanding of global historical diversity.

\section{Narrative History and Its Telos}

The teleological basis of narrative histories, as opposed to compilations of facts in chronological order, is communication and achievement of historical understanding. Perhaps it is true that "no given theory of history is convincing... on the basis of its adequacy as an 'explanation"” (White, 1973: p. 429); however, objective explanation and communication are not synonymous. It is inconceivable for an author to create a narrative history that does not serve as an attempt to communicate. Indeed, even in cases where none but a history's author functions as an audience, the author communicates and seeks to nurture an understanding with themself. ${ }^{4}$ While naming the audience as the radically essential operator in narrative is not necessary for our purposes, the opposite radical position, namely the denial of any function to the audience, is a blatant impossibility. Narrative is impossible without audience, and as Ricoeur reminds us, "history... cannot sever every connection with narrative without losing its historical character” (Ricoeur, 1984: p. 177). Therefore, it is misguided at best to attempt to address history without addressing narrative and its accompanying audience, author, and telos.

Criticized from both sides of the science/art divide as narrative history may be, its theorists-historiographers and philosophers-cannot ignore the valid and constructive points raised by detractors (White, 1978: pp. 40-41). If narrative history is to assert its ability to achieve its telos, it must do so within the overall context of the intellectual academy. Both literalist and interpretive historians are, perhaps unfairly, forced into "the situation of a judge” (Ricoeur, 1984: p. 175). In order to achieve a coherent theory, history must "break through two resistances" (Ricoeur, 1984: p. 163), the resistance to history as intrinsically linked to truth in fact and event, and to history as intrinsically linked to the interpretative endeavors of humanity. The Fabian strategy often employed by theorists of narrative history may perniciously obscure the potential for narrative history to have a fruitful life within the academy.

\section{Truth and Type}

Most mundane concepts of "truth" treat it as accurate correspondence between one's thoughts or concepts, or the concepts collectively assented to by a group, and independent reality. Brute correspondence between language and truth is the product of an ontological and linguistic position that one's knowledge accurately reflects the real ${ }^{5}$ world. Indeed, this correspondence may be buried within the notion and practice of language. Language may contain what Ricoeur refers to as "the ontological presupposition of reference, a presupposition reflected inside of language itself as a postulate lacking any imminent justification". Ricoeur continues, "Language is for itself the order of the Same. The world is its Other" (Ricoeur, 1984: p. 78).

\footnotetext{
${ }^{4}$ Perhaps a dialogue between aspects of the author's self in different times. I leave it to others to explore authorship, audienceship, and self over time. ${ }^{5}$ Whatever one holds "real" to mean. Potential substitutes include "material" and "objective."
}

Taking these points immediately, a point of irreconcilable difference is reached. Ricoeur reconciles the internal coherence, the "Same"ness of language for itself, with the "Other"ness of the world by demonstrating that externalization required for language to reflect the world is a “...counterpart of a prior and more originary notion, starting from our experience of being in the world and in time, and proceeding from this ${ }^{6}$ ontological condition towards its expression in language” (Ricoeur, 1984: p. 78).

Though language and knowledge grow from the same originary condition, a number of effective criticisms have been levied against the notion of truth-as-correspondence. Most notably is the section entitled "Mirroring” in Richard Rorty's Philosophy and the Mirror of Nature (Rorty, 2009: pp. 129-312). Rorty's critiques mirror those described above. In response to these difficulties, I offer two responses. First, incommensurable discourses and ideas may be addressed through "hermeneutics". Rorty's hermeneutics is “...the study of an abnormal discourse from the point of view of some normal discourse-the attempt to make some sense of what is going on at a stage where we are still too unsure about it to describe it, and thereby to begin an epistemological account of it” (Rorty, 2009: p. 320). Rorty describes the difference between his notion of hermeneutics and his notion of epistemology as:

...one of familiarity. We will be epistemological where we understand perfectly well what is happening but want to codify it in order to extend, or strengthen, or teach, or "ground" it. We must be hermeneutical where we do not understand what is happening but are honest enough to admit it (Rorty, 2009: p. 321).

Second, the description of epistemologies is certainly more plausible in realms where commensurability is, or is apparently, ready to hand. These realms include (some portions of) science and math. It will serve us well to allow for the establishment of epistemologies in certain areas of human life, in order to allow for the distinctly different process of hermeneutics in others. This process is particularly applicable to novel and extreme histories, because to claim perfect understanding would be to deny their novelty.

An alternative to the correspondence theory of truth that grounds Rortian epistemologies is the use of commensurability, or mutual, practical understanding as the measure of a concept's (or thought's) truth. In addition to Rorty's descriptions, David Carr describes the role of commensurability in theories of narrative history, writing:

In our discussion of common experience we spoke of the role of the common object, which refers back to the intersubjective or we-subject ${ }^{7}$. If we consider the object as a temporally extended event... then the unity of the experience, as with the individual, must be procured by a projective-retrospective grasp. In the reciprocal awareness of the individuals, this grasp is affected by a group in relation to this particular experience: "we" experience this object or event together (Carr, 1986: p. 147).

In the communal experience of history, there is truth due to the practical assent to common notions of history. This common assent allows for discourse based on fixed points, or fixed notions. This is not merely common experience-it is rather "experience $a d^{8}$ actions" (Carr, 1986: p. 149). These actions

\footnotetext{
${ }^{6}$ Emphasis added.

${ }^{7}$ Rather than reference to an objective truth. This is not correspondence between notions of truth and the objective world, but rather reference to other agents and the "we" subject.

${ }^{8}$ Emphasis added.
} 


\section{Z. DONNELLY}

include and allow the practice of history. If for no other reason than a preference for applicability, we should prefer to work with the practice and commensurability model of truth, rather than the correspondence model.

As it pertains to historical event and fact, the question of truth becomes critically important. Especially when considering types of interpretative narrative history, one must decide to what extent certain descriptive elements, such as the horror of the Holocaust or the triumph of man's first flight, are a matter of immutable truth, and to what extent it is a matter of mutable interpretation. Had we held fast to a correspondence theory of truth, history would potentially be bare of descriptive truth. As Ricoeur writes, "One class of descriptions is missing from the absolute chronicle...that is, the whole truth concerning this event cannot be known until after the fact...” (Ricoeur, 1984: p. 145). The descriptive elements of the possible truth of an event cannot be known until after the event, yet the correspondence theory of truth would preclude such descriptive elements by demanding that truthful notions reflect the event itself atemporally. If descriptions reflected the truth over time, they would not have the immutable pure correspondence sought by the theory.

Additionally, if history is to be an instantiation of correspondent, reflective truth, it should be capable of reflecting any span of time, including the present. Yet "there is no history of the present" (Ricoeur, 1984: p. 147). A history of the present is impossible. If history is to be equated, however vaguely, with a correspondence-based theory of truth, and if it is possible for there to be correspondent truths about the present ${ }^{9}$, there should be a transitive possibility of establishing a history, however rudimentary, of the present. Carr supports this conclusion in describing how history must be experienced either retrospectively (in the case of complete histories) or "quasi-retrospectively," (in the case of portions of a historical concord which is still being played out) (Carr, 1986: pp. 78-79). In addition to Ricoeur's investigation and Carr's description of history, common understanding and intuition assert that this is a patent impossibility. Asserting a history of the present is as nonsensical as asserting a history of the future.

Truth as commensurability allows for relationships and descriptive elements. As Michael Dummet writes, "The concepts of truth of a statement, the ground of an assertion, and the point of making one indeed belong to our ordinary linguistic repertoire; they are nevertheless second-level concepts, used to comment on our employment of language 10" (Dummet, 1991: p. 167). The emphasis is then placed on the "employment of language." This employment, and commentary on employment, is the foundation of the concept of truth as practice and commensurability. With a theory of truth as practice and commensurability, there is room for the recreational kicking of puppies to be viewed as a true abomination. It is a true abomination because we employ language to describe a commensurable condemnation of the act. Indeed, because "history has objectivity ${ }^{11}$ as a project" and because "it can pose the limits of objectivity as a specific problem” (Ricoeur, 1984: p. 176) the concept of referential truth-“objectivity” in Ricoeur's words-is a poor candidate for inclusion in the theoretical structure and practice of history.

Is it possible for truth to survive the refinement that changes

\footnotetext{
${ }^{9}$ Such as the true phrase, "I am currently sleepy".

${ }^{10}$ Emphasis added.

${ }^{11}$ Read, perhaps too charitably, as the concept of referential truth.
}

the raw "truth" of fact and event into truth in narrative history? In discussing the propensity for historians to view facts as given rather than as the results of certain epistemological and methodological frameworks, Hayden White writes: "It is the same notion of objectivity that binds historians to an uncritical use of the chronological framework for their narratives" (White, 1978: p. 43). If historians view the chronology that comes quite naturally to an artificial emplotment as itself a given truth-as Ricoeur demonstrates in his "Defenses of Narrative" in Time and Narrative (Ricoeur, 1984: p. 146) - there exists, prior to discussion of either the truth of particular facts and events (the focus of literalist narrative history), or prior to discussion of the truth of the themes and meaning of history (the focus of interpretive narrative history); a potentially pernicious false premise.

Particular types - or genres — of interpretive narrative history may fail to communicate the truth of history. For example, a lighthearted retelling of how I watched a child kick a puppy to death for the enjoyment of doing so in a comedic genre would likely fail to communicate the abominability of the act. Though such an act might exist in a larger context, one that might diffuse the sharper aspects of my true description of the event as abominable, the event itself is nonetheless closed. This is how Carr describes such closure: "In terminations, conclusions, achievements, time is provided with a closure by the very activities in which we are involved" (Carr, 1986: p. 81). These terminations close histories, and allow for genre or type to be connected with histories. However, because histories exist in a global and grand-historical context, the bright lines defining closure are themselves unnatural, or at best falsely understood by humans to be brighter and stronger than they really are. Carr describes this entropy as a "tendency" or "capacity, to fly apart or to fragment, thus losing their narrative coherence" (Carr, 1986: p. 88). This potentially false (or potentially vague) application of division, and the questionable understanding of the division as natural, leads to failures of type to be able to reflect the descriptive truth of a history. If one seeks perfect concordance between notions of truth and history in genre ${ }^{12}$, one will be disappointed due to failures of both truth and the structures of division and termination that permit genre to be assigned to a history. This tendency is surely exacerbated by the difficult topics of novel parts of history.

Within intentional human disciplines such as science, history, or even the execution of a type of art, epistemology of the kind described by Rorty (Rorty, 2009) is certainly ${ }^{13}$ possible. Indeed, thinkers of a previous era were able to agree on "a specific mode of discourse” (White, 1978: p. 428). Issues of knowledge within a framework of practical commensurabilities are certainly subject for fruitful discussion. In this way, different types of history may themselves have internal epistemologies. White describes the internal epistemologies of (what may be described as) literalist history and interpretive history, stating that the former looks to causal interaction similar to that found in physical science, and the latter looks to coherence of story and emplotment (White, 1978: pp. 54-55). Ricoeur describes the role that time and understanding play as the "solution to the paradox of distention and intention” (Ricoeur, 1984: p. 67). Carr, on the other hand, takes narrative as a structure of everyday experience. Despite their differences, both initially appear to attempt a presentation of a Rortian epistemology of story.

\footnotetext{
${ }^{12}$ In addition, perhaps, in other areas of historical inquiry.

${ }^{13}$ Or at least contentiously.
} 


\section{Z. DONNELLY}

The basic elements of their philosophies are understood and serve as solid points of departure for discussion within the philosophy of story, and the effectiveness of their ideas can be judged and debated within a steady framework.

Difficulty arises when one seeks to reconcile the frames of Ricoeur and Carr's investigations with investigations of global scope. These points of incommensurability call for what Rorty terms a "hermeneutic"14 (Rorty, 2009). Ricoeur, indeed, recognizes this discontinuity, citing an example of "complementary" yet divergent sociological and historically causal perspectives. "Causal explanation” goes along with other modes of explanation, despite differences (Ricoeur, 1984: pp. 188-189). Even when one attempts to "methodologically" anchor narrative history in such a general frame as "the first person" (Carr, 1986: p. 124), there is an element of unnecessary and perhaps pernicious rigidity. Anchoring narrative history in either communal or singular subjectivity precludes, or at best denigrates, the excluded frame. It is easy to see where such exclusion or denigration impoverishes the tools at humanity's disposal when confronting the aporias of novel history. Failures of genre or type to accurately reflect the truth of historical fact and event are themselves general failures of what Richard Rorty describes as "epistemologies". These epistemologies see "hope of agreement as a token of the existence of common ground which, perhaps unbeknown to the speakers, unites them in a common intentionality" (Rorty, 2009: p. 318).

In order for one to establish a regional epistemology, there must be points of commensurability. Often, aspects of the truth of historical fact and event do not allow for widespread commensurability. This difficulty is so acute as to lead historiographers such as Hegel, Droysen, Nietzsche, and Croce to reject objectivity altogether, and treat it as a "myth.” (White, 1978: p. 52). More recent historians have been explicitly positive, and suggested that history is "nothing but interpretations" (Ibid. 55). In addition to the fact that no regional epistemology is possible without some assent to objectivity, the assault on general objectivity cuts deeper and far beyond the study of history. ${ }^{15}$ What concerns the region of narrative history is failure to find practical commensurability beyond the trivial (language, logic, and other forces of order in the world).

This difficulty is acutely true in regards to descriptive truth. If one assents to the truth in the descriptive portion of the statement "kicking puppies for recreation is abominable", one assents to a point of commensurability in criteria for abominability and in the act of recreationally puppy-kicking satisfying such criteria. While both points seem intuitively commensurable, benign clarifying questioning may conceivably throw both points into doubt. Asking such questions as "What is it to be abominable?" and "How does the act of puppy-kicking qualify as abominable?” is both valid and fruitful. In diligently answering such questions, one must adopt a perspective of (at least momentary) issue-particular agnosticism. Instances of such agnosticism are easily extended to questioning activity, and indeed, to daily life. In mundane moments when clarifica-

\footnotetext{
${ }^{14}$ The extent to which Rorty's concept of hermeneutics and epistemology are faithful to the classical or mainstream understandings of the concepts are clearly debatable. For clarity's sake, throughout this paper any discussion of hermeneutics and epistemology refers to Rorty's concept. The potential schism between his concepts is the subject of other investigations.

${ }^{15}$ Indeed, if one is to question objectivity in general, virtually all intelligible endeavors, and not merely academic endeavors are in question. As such, we will allow charges describing the failure of general objectivity to be put aside for a different investigation.
}

tion between people is required in order for practical interaction to continue, we have brief instantiations of the practical problems of establishing and maintaining commensurability. When dealing with the practical issues of communicating history, the vagaries of time and the complexities of history magnify difficulties.

The inability to achieve commensurability, the inability to find some historical truth, lies not in a failure to communicate, but rather, in a failure of expectation. The expectation that particular genres will correspond to particular true aspects of history is once again falling into the difficult and narrow concept of truth as correspondence. This is a failure of expecting a nonscientific ${ }^{16}$ discipline to operate as a science founded upon firm epistemological notions. As White remarks in discussing the move beyond history founded on fixed notions:

I have suggested that the nonscientific or protoscientific nature of historical studies is signaled in the inability of historians to agree-as the natural scientists of the seventeenth century were able to-on a specific mode of discourse... As a result, historiography has remained prey to the creation of mutually exclusive, though equally legitimate, interpretations of the same set of historical events or the same segment of the historical process (White, 1973: p. 428).

This general failure is especially acute when considering novel and extreme historical events. Rather than be cause for despair, this failure should prompt theorists to move beyond attempts at epistemology and into the realm of hermeneutics.

Rorty describes the discussion of a subject around which there is incommensurability as "Hermeneutics". This normal discourse is the (potentially natural) narrativization of history, life, and fact and event described by theorists such as Carr, Ricoeur, and White. It is this kind of critical and theoretical discussion which must accompany the practice of diverse, unbounded application of narrative history to historical fact and event. This dynamic process is not, as Ricoeur calls it, an "epistemology of historical knowledge" drawing benefit from "modes of explanation” (Ricoeur, 1984: p. 166) ${ }^{17}$, but rather a discussion of, and around, points of incommensurability. Rather than advocating and implementing - and thereby bounding and codifying - a framework of openness, discussion of narrative history ought to recognize narrative history as an opening and dynamic, self-defining phenomenon. Application of epistemological and correspondence standards to narrative-even when such standards assert openness - confound the practice of addressing history where there are points of incommensurability. Such assertions of openness attempt to impose a standard, namely openness itself, onto a practice that is the dynamic revelation of commensurability and standards. Such imposition is itself pernicious to the endeavor.

\section{Opening Space}

The open space I wish to set against a rigid concept of mod-

\footnotetext{
${ }^{16}$ Or at best, quasi-scientific.

${ }^{17}$ While Ricoeur undoubtedly has a different sense of the word "epistemology" than Rorty, the benefits to knowledge from diverse "modes of explanation", contain the undeniable sense of an epistemic clarification, a gaining of multiple metaphorical perspectives by which a knowing agent may develop a fully justified true belief. This quest for justified true belief is the hallmark of Rorty's concept of epistemology, as well as the common concept of epistemology. Therefore, it is appropriate to draw a distinction between a clarification of knowledge and a discussion of points of incommensurability (Rorty's hermeneutics).
} 


\section{Z. DONNELLY}

ernism (or any type/genre preference) is one in which a discus-

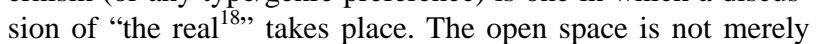
Ricoeur's "remarkable intersecting of the possibilities opened by the diverse narrative categories involved" (Ricoeur, 1984: p. 167), but rather the involvement itself of "diverse narrative categories" and their treatments of the history writ large. The space is itself the discussion, rather than a defined area (whether fictional or real). Perhaps, then, it would be better described as an "opening" space rather than an "open" or "opened" space. As Rorty writes, "...hermeneutics is an expression of hope that the cultural space left by the demise of epistemology will not be filled - that our culture should become one in which the demand for constraint and confrontation is no longer felt" (Rorty, 2009: p. 315). This space is not predefined nor constrained in order to facilitate discussion and dialogue (it could then be pejoratively labeled "open-ism"), but it is whatever space the discussion occurs in. A cosmological analogue would be the physical universe, which itself has no boundaries, save those in which the physical universe occurs. ${ }^{19}$ Similarly, any functional opening narrative space is that which does not fill boundaries, and does not admit of a central point to which one may appeal.

Ricoeur's statement, "History does not have a method but it does have a critique and a topic” (Ricoeur, 1984: p. 173), provides alternate terms for the present discussion, ones which allow for a further elucidation of the argument against a calcified open space. The topic of history, or of particular histories, is quite clear-it is the event and fact. Ricoeur appeals to Vico and Aristotle for his concept of topic as "topoi or "commonplaces"”. These “commonplaces” are "appropriate questions” (Ricoeur, 1984: p. 173). Perhaps put too generally, the appropriate questions of history are of event and fact. Though history has appropriate questions, it does not have method. The method of history as science, if it did indeed exist, would be a Rortian epistemology - a well-defined system of true references and commensurable, practical truth. As we have seen, this is not the case. Instead, history has a "critique". Like all critiques, the critique of history, and therefore of historical narrative, is more of a discussion than a rigorous epistemology. The critique is, I suggest, the description that accompanies the opening of space for historical narrative and historical discussion. It is clear that there is a double opening, first in the execution of narrative histories, and in the accompanying theoretical discussion of the opening. In the second discussion of the opening there ought to be what Ricoeur names a "genesis of meaning" (Ricoeur, 1984: p. 228). It falls to the theorists to ensure that this is indeed a genesis, rather than a prescription of meaning. This responsibility is met in discussion.

The execution of narrative history allows the opening of discursive space. Indeed, the execution of diverse narrative histories is itself the opening of the critical discursive space. Criticism and theory or narrative history, however, seem to lag behind practice. Hayden White, whose theory of narrative lends much to this essay's argument, himself advocates a distinct kind, or type/genre, of narrative history when confronted with novel or extreme histories. White uses the example of the Nazi attempt at exterminating Europe's Jewish population. Though it was both extreme and novel, White concludes his study of nar-

\footnotetext{
${ }^{18}$ However one understands concepts of reality etc.

${ }^{19}$ Prior to "the big bang", the entire physical universe was a point, and then it expanded, but it did not expand to fill boundaries, and it did not expand from a center.
}

rative histories of the holocaust by writing that “...I do not think that the Holocaust...is any more unrepresentable than any other event in human history". White goes on to say that it requires "the modernist style, that was developed in order to represent the kind of experiences which social modernism made possible...” (White, 1992: p. 52). Yet the modernist style, no matter how much it aspires to be a space of open discourse, remains a type. The assertion that modern type corresponds, or mirrors, modern history implicitly excludes the possibility of non-modern types of narrative history. The assertion that any type, including modernism (and post-modernism), corresponds directly to fact and event in history is the false premise that has been revealed throughout this essay. Secondly, the implicit exclusion of other types is pernicious to an opening, hermeneutic discourse.

This example, however, does not demonstrate that theorists are opposed to the dynamic play of the Rortian hermeneutic in the historical academy. Quite the contrary, many theorists including as Hayden White, who has displayed a tendency towards calcification (in the "modernist style"), also hint at an acceptance of a dynamic opening. As White himself writes,

...the governing metaphor of an historical account could be treated as a heuristic rule which self-consciously eliminates certain kinds of data from consideration as evidence. The historian operating under such a conception could thus be viewed as one who, like the modern artist and scientist, seeks to exploit a certain perspective on the world that does not pretend to exhaust description or analysis of all of the data in the entire phenomenal field, but rather offers itself as one way among many of disclosing certain aspects of the field (White, 1978: p. 46).

The rigidity identified in the previous White reference is the result of this "one way among many of disclosing" mutating into the way, or more precisely, the prescribed way to view historical narrative. The conception White describes is part of an unbound academic Rortian hermeneutic, one that exploits the commensurable references which the particular perspective uncovers and addresses points of incommensurability through active discussion. The exploitation of commensurability and the establishment of a plurality of perspectives should be judged by theorists on its effectiveness in achieving the idiosyncratic telos of any particular type of narrative history, rather than the way that the particular type corresponds to particulars of fact and event.

Furthermore, White describes historical narratives as both "models of past events and processes" and "complex(es) of symbols which gives us directions for finding an icon of the structures of those events in our literary traditions" (White, 1978: p. 88). While the combination of these two concepts is effective, it should not be presented as a modalized choice between the two regarding one particular narrative history, but rather as a dynamic play between the two concepts in the larger discussion of history. Insofar as historical narratives serve as models, they do not reflect the inescapable interpretation of history. Insofar as historical narratives serve as complexes of symbols, they do not reflect the commensurable truth found within literalist models. Yet both contribute, together, and often through their clash, to a fruitful wider historical discourse.

In Hayden White's "Historical Emplotment and the Problem of Truth," he argues for the use of a modern, open style to address modern types of historical event. This prescription of style is where discourse becomes dangerously calcified. Indeed, 
it is the assertion or prescription of style, based on a supposed correspondence of type to fact and event that devolves historical discussion into vain attempts at epistemology. Yet the examples cited by White, such as Spiegelman's Maus, are themselves not epistemological attempts at reckoning with history. However much he cites them as examples of modern narrative history (White, 1992), they eschew genre and type. Instead, they emplot and execute narrative histories as part of a wider and unbounded discussion. This leads one to believe that the dangerous rigidity previously identified is primarily within theory rather than practice. Indeed, it is most likely only present when historiography becomes prescriptive. When prescribing type or style, historiography moves away from theory and begins to assert itself (vainly) upon a practice that, based on White's examples and many others, does not need to be bound by prescription. The continual opening of narrative history serves its purpose without having to aspire to a standard described by theorists.

\section{Postscript: Response to Charges of Relativism}

The operation of this proposed opening space is not relativism as one might initially suspect. Working out points of commensurability is the product of the wider Rortian hermeneutic. As such, when one turns attention to particular truths of fact and event, active and iterated agnosticism is the result. Another way to describe this web of interconnected agnosticism is historical "cosmopolitanism," which White describes as the abandonment of true ${ }^{20}$ perspectives (White, 1978: p. 47). The abundance of agnosticism regarding truth and fact, and indeed regarding perspective and type, should not be confused for radical relativism. Comfort with agnosticism is something empirical scientists are familiar with and one which narrative history theorists should become comfortable with as well. Put differently, type in narrative history should function as what White calls a "system of notation.” Within a particular system of notation, one should seek understanding (White, 1978: p. 47)— commensurability, to use Rortian language- but remain agnos- tic as to the place of the notated items' place in any purportedly universal system of truth and reference. This relative agnosticism is natural because it is the same absence of an authority (such as particular truths) to which one may appeal that occurs in any pre-epistemological discussion. There must be un-centered, boundless discussions in order to reveal and define the center and any possible boundaries. ${ }^{21}$ Such relativism is, by its nature, unsettling; however it is not something which ought to be avoided, because it has a natural place in our endeavor to understand (to understand the world, history, each other, etc.).

\section{Acknowledgements}

I wish to thank Richard Kearney for his advice and encouragement, Nastassja Marshall for her support, and Adrienne Bogacz for proofreading and initial review.

\section{REFERENCES}

Carr, D. (1986). Time, narrative, and history. Bloomington: Indiana University Press.

Dummet, M. (1991). The logical basis of metaphysics. Cambridge, MA: Harvard University Press.

Ricoeur, P. (1984). Time and narrative. Chicago, IL: The University of Chicago Press.

Rorty, R. (2009). Philosophy and the mirror of nature (30th-Anniversary Edition). Princeton: Princeton University Press.

White, H. (1973). Metahistory. Baltimore: The Johns Hopkins University Press,

White, H. (1978). The burden of history. Tropics of Discourse (pp. 27-50). Baltimore: The Johns Hopkins University Press.

White, H. (1978). Historical text as literary artifact. Tropics of Discourse (pp. 81-100). Baltimore: The Johns Hopkins University Press.

White, H. (1978). Interpretation in history. Tropics of Discourse (pp. 51-80). Baltimore: The Johns Hopkins University Press.

White, H. (1992). Historical emplotment and the problem of truth. In S. Friedlander, Probing the Limits of Representation (pp. 37-53). Cambridge, MA: Harvard University Press.

\footnotetext{
${ }^{20}$ In this instance, White seems to be using the correspondence/reflective model of truth.

${ }^{21}$ The same opening space operates in all pre-epistemological discussions. For example, prior to the establishment of Newton's laws, there was a long (centuries long) discussion in an opening space concerning the physical laws of the world. Once Newton revealed and communicated certain laws, a center and functional epistemological truth was established. The advent of quantum mechanics threw this center into doubt, and (at least as far as I know) there is an important discussion taking place in the scientific community whose goal is to reconcile Newtonian physics and Einsteinian relativity with quantum mechanics and thereby reestablish a centered, defined space for science. This discussion is taking place in an opening space, a space that is open because of the discussion. This space also contains relativism and issue-specific agnosticism, as do all pre-epistemological discussions.
} 